\title{
Removal of Reactive Dye Using Solvent Impregnated Resin
}

\author{
Anjali Awasthi, Sakshi Batra, and Dipaloy Datta
}

\begin{abstract}
In this study, Reactive Blue-13 (RB-13) dye removed by solvent impregnated resin (SIR: Amberlite XAD-7 impregnated with Aliquat-336) at different operation conditions. Batch adsorption studies were dispensed out to gauge the effect of solution $\mathrm{pH}$, dosages, kinetic, temperature, concentration and $\mathrm{NaCl}$ salt on the adsorption capacity of the adsorbents. Three kinetic models were chosen to suit the kinetic data; pseudo first order, second order, and intraparticle. diffusion. It had been determined that RB-13 dye adsorption followed pseudo-second-order kinetics. Adsorbent SIR was characterized by Fourier transform infrared spectroscopy (FTIR), Scanning electron microscope (FE-SEM) and EDX. Solvent impregnated resin (SIR) was regenerated with $80 \%(\mathrm{v} / \mathrm{v})$ ethanol aqueous solution for reuse.
\end{abstract}

Index Terms-Adsorption, aliquat-336, reactive blue-13, XAD-7.

\section{INTRODUCTION}

In textile industries, its reported that commonly more than 100,000 dyes with over $7 \times 10^{5}$ tones of dyestuffs ( a soluble substance used for coloring that contain various raw materials that remain after dying process, spin-off, diluting agent, etc.) produced yearly [1].

It also found that unexpended dyestuffs are indestructible, non-biodegradable, toxicant and contain various mutagenic and carcinogenic properties. These have an effect on the ecosystem, individuals, aquatic plant and mammal causes various diseases [2]-[4]. A number of studies have pointed out that occurrences of several disease among textile industries staff such as Bladder cancer, Cancer mortality, Breast cancer, Lung cancer, Oral cavity, and pharynx cancer, nephrosis, skin eruption [5]-[20]. Industrial effluent containing dyes additionally causes such disorders.

So removal of such dyes from industrial effluent could be a challenge to each the textile trade and wastewater treatment facility for treating this effluent. It is compulsory that unused dyes must be removed before discharging the effluent water to the surroundings to evade health hazards and destruction of the scheme.

Major categories for dyes removal are biological, chemical, and physical methods. These methods contain several

Manuscript received February 25, 2019; revised April 22, 2019. This Work was supported by Science \& Engineering Research Board (SERB), a statutory body of the Department of Science \& Technology, New Delhi, India for financial support under Early Career Research Award (EC Engineering Sciences). Removal of Reactive Dye using Solvent Impregnated Resin.

The authors are with the Department of Chemical Engineering Malaviya National Institute of Technology (MNIT), Jaipur, Rajasthan-302017 (anjaliawasthi33@gmail.com,

Dipaloy@gmail.com). techniques, Flocculation-Coagulation, adsorption, membrane separation, electrochemical, reverses osmosis, ozone oxidation, sand biological treatment etc. Flocculation-coagulation method is not so effective because the dye was produced a multiplex with the flocculant, so removal and recycle of dye causes trouble. Membrane separation and reverse osmosis method are expensive for the economic point of view. Adsorption is one of the best cheap processes for removal of dyes.

The large portion of dyes is Azo Dyes (i.e contain aromatic hydrocarbons). Other classifications done according to the structure of dyes are anionic and cationic dyes. Today reactive dyes are popular among textile industries due to its give permanent coloration to cellulose textile substrates and also color did not fade or discolor on laundering. Various types of reactive dyes used in textile industries depends upon the medium temperature (i.e. Cold brand dye: Dyeing process is carried out at room temperature, Hot brand dye: Dying occurs at $60^{\circ} \mathrm{C}$, High Exhaust brand reactive dyes: Dyeing process is carried out around $80-90^{\circ} \mathrm{C}$ ). In dying process $80 \%$ of reactive dye participates for dying the fiber, i.e. $20 \%$ remains within the effluent; this is often the hydrolyzed dye that can't be reused for coloring.

This unused dye remains within the effluent treatment plant. Dye concentrations range $10-25 \mathrm{mg} / \mathrm{L}$ are cited as being present in dye section effluents [21]. After combining with different effluent streams, the concentration of dyes is more insipid. The limit of the concentration of some cyanogenic dyes in water is $1.0 \mathrm{ng} / \mathrm{L}$.

In this investigation, AmberliteXAD-7 Resin impregnated with Aliquat-336 was prepared for removal of Reactive Blue-13 dye. The effecting parameters such as adsorbent dose, dye concentration, $\mathrm{pH}$, time, temperature and salt concentration on the performance of the adsorption process were also studied. Effect of Concentration was studied and therefore the pseudo-first-order, the pseudo-second-order, and Elovich models were usable to describe adsorption dynamics. Regeneration of SIR was done by $80 \%$ (v/v) ethanol aqueous solution, and then reused it up to several times.

The purpose of this study is to shows that the un-used reactive dyes will be removed from the effluent by adsorption process using solvent impregnated resin.

\section{MATERIALS AND METHODS}

\section{A. Materials}

Amberlite XAD-7 resin (20-60 mesh) was equipped by Sigma-Aldrich (Merck, Germany). This nonionic, porous 
resin often contains a polyacrylic acid ester group (molecular formula- $\left.\left[\mathrm{CH}_{2}-\mathrm{CH}(\mathrm{COOR})\right]_{\mathrm{n}}\right)$. Structure of resin was porous, $80-85 \mathrm{~A}^{0}$ pore diameter and $380 \mathrm{~m}^{2} / \mathrm{g}$ surface area. Reactive Blue-13 dye contains Azo group (M.Wt.-866.06g/mol; molecular formula- $\mathrm{C}_{29} \mathrm{H}_{16} \mathrm{ClN}_{7} \mathrm{Na}_{4} \mathrm{O}_{14} \mathrm{~S}_{4}$ ) was supplied from Alpha Aesar, Britain. Physical properties and chemical structure of RB-13 dye is shows in Table I and Fig. 1. The stock solution of RB-13 dye was prepared in distilled water (via distillation column, in Material Research Centralized laboratory of MNIT, Jaipur). Analytical reagent (AR)-grade chemicals (Ethanol, $\mathrm{HCl}$, and $\mathrm{NaOH}$ ) purchased from Merck, India, and Aliquat-336 was purchased from Sigma.

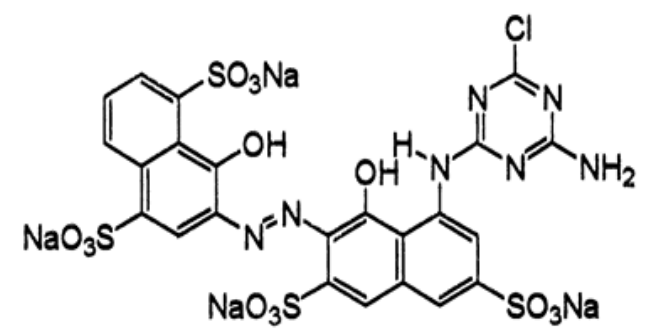

Fig. 1. Chemical Structure of reactive dye Reactive Blue-13.

TABLE I: PhySICAL PROPERTIES OF REACTIVE BLUE-13 DYES

\begin{tabular}{ll}
\hline \hline Properties & $\mathrm{RB}-13$ \\
\hline Molecular Formula & $\mathrm{C}_{29} \mathrm{H}_{16} \mathrm{ClN}_{7} \mathrm{Na}_{4} \mathrm{O}_{14} \mathrm{~S}_{4}$ \\
& \\
Molecular Weight & 866.06 \\
Appearance & Dark Blue \\
Solubility ( at $\left.20^{\circ} \mathrm{C}\right)$ & $110 \mathrm{~g} / \mathrm{L}$ \\
Solubility in water & Soluble in water \\
Nature & Anionic \\
\hline
\end{tabular}

\section{B. Preparation of Adsorbent}

There are various methods for the preparation of impregnated resin i.e. dry impregnation, wet impregnation etc. We prepared resin by wet impregnation techniques. In this process, the first washing of resin was done with ethanol then with DI water for removal of impurities. For that resin and ethanol mixture was taken in a borosil beaker then put it in magnetic stirrer for $2 \mathrm{hr}$. After that resin was filtered and filtered resin with DI water put in magnetic stirrer for washing until the $\mathrm{pH}$ was neutral. Then the resin was dried overnight in open air after that dried this resin for $12 \mathrm{~h}$ in an oven at $313 \mathrm{~K}$. In that case this washed resin impregnated with a certain ratio of Aliquat-336. For the preparation of 1 Ratio of SIR, 1 gram per $11.28 \mathrm{ml}$ Aliquat-336 in $40 \mathrm{ml}$ hexane was mixed in a flask and placed it in a water bath shaker for $24 \mathrm{~h}$ (in this study we used 0.25 Ratio of SIR, calculated as per $2.793 \mathrm{ml}$ Aliquat-336 in $40 \mathrm{ml}$ hexane). Hexane was used as a diluting agent for viscous Aliquat-336. Then this impregnated resin was again left overnight in open air for drying, after that, it was kept in an oven at $313 \mathrm{~K}$ for 24 $\mathrm{h}$. Then the prepared resin was kept in a desiccator.

\section{Characterization}

Characterization of SIR and used SIR(i.e. after adsorption of Reactive Blue-13) was done by using FTIR and FE-SEM. FTIR data was taken in a range of $4000-400 \mathrm{~cm}^{-1}$ by FTIR
Spectrum 2 (Perkin Elmer, USA). Different peaks of percentage transmission were studied and analyzed. The surface morphology features of unprocessed, modified and used impregnated resin XAD-7 were observed by Scanning Electron Microscopy (FE-SEM) (Nova NanoSEM 450, Perkin Elmer, USA) and Energy dispersive X-Ray (EDX).

\section{Adsorption Experiments}

Batch studies at numerous conditions were performed for determination of adsorption phenomena. The effect of adsorbent dose range 0.01-0.3 g, was studied by taken $10 \mathrm{ml}$ of $50 \mathrm{mg} / \mathrm{L}$ dye solution in flask at temperature $303 \pm 2 \mathrm{~K}$, and put these flask in water bath shaker for definite time intervals. A kinetic study was done, up to $180 \mathrm{~min}$ at an optimum dosage of SIR $0.1 \mathrm{~g}$ and an initial concentration of dye solution $50 \mathrm{mg} / \mathrm{L}$. To review the effect of temperature for removal of $50 \mathrm{mg} / \mathrm{L}$ dye, experiments were carried out at temperature range 303-333 K. For the study of the effect of $\mathrm{NaCl}$ salt on adsorption, $50 \mathrm{mg} / \mathrm{L} \mathrm{RB}-13$ dye, $0.1 \mathrm{~g}$ dose of adsorbent were taken at a distinct concentration of salt ranges $1000-15000 \mathrm{mg} / \mathrm{L}$ for $3 \mathrm{hr}$ at $303 \mathrm{~K}$. So the optimum parameters for the dye removal process was defined by varying one parameter and kept other parameters constant. It was initiate in this study that maximum removal percentage $(\sim 99 \%)$ of dye was obtained at following optimum parameters $0.1 \mathrm{~g}$ dosage, $2 \mathrm{~h}$ time, $50 \mathrm{mg} / \mathrm{L}$ dye concentration and at $303 \mathrm{~K}$ temperature.

The adsorption capacity $\left(q_{e}{ }^{0}\right)$ in $\mathrm{mg} / \mathrm{g}$ of adsorbent was calculated by the following Equation.

$$
q_{\mathrm{e}}^{0}=\frac{\left(C_{0}^{\prime}-C_{\mathrm{e}}^{\prime}\right) \cdot V}{m_{a}}
$$

where $C_{0}^{\prime}(\mathrm{mg} / \mathrm{L})$ is the initial RB-13 dye concentration and $C_{\mathrm{e}}^{\prime}(\mathrm{mg} / \mathrm{L})$ is the equilibrium concentration of the dye, $\tilde{V}(\mathrm{~L})$ is the volume of the dye solution, $m_{a}(\mathrm{~g})$ is the amount of adsorbent. The removal efficiency was calculated by the following equation.

$$
\text { Removal \% }=\frac{\left(C_{0}^{\prime}-C_{\mathrm{e}}^{\prime}\right)}{C_{0}^{\prime}} \times 100
$$



Fig. 2. FTIR analysis of impregnated XAD-7 resin and Impregnated XAD-7 resin after adsorption.

\section{RESUlTS \& DisCUSSION}

\section{A. Characterization: FTIR Analysis}

A Fourier Transform Infrared spectrometer (FTIR) 
(NEXUS-650, America) was used to analyze the dominating functional groups on the adsorbent surface. The strong peak around $3439 \mathrm{~cm}^{-1}$ represents the hydroxyl groups $-\mathrm{OH}$, the bond at $2927.4 \mathrm{~cm}^{-1}$ is attributed to the presence of the $\mathrm{C}-\mathrm{H}$ bond. $\mathrm{C}-\mathrm{Cl}$ stretching peak shown at $755 \mathrm{~cm}^{-1}$. Bending of $\mathrm{O}=\mathrm{S}=\mathrm{O}$ peak noticed at $598 \mathrm{~cm}^{-1}$. C-C, C-H stretching vibration noticed a sharp peak at $1060.45 \mathrm{~cm}^{-1}, 2589.3 \mathrm{~cm}^{-1}$. There found a more sharper and higher intensity peak in impregnated XAD-7 resin at $1623.6 \mathrm{~cm}^{-1}$ which shows the presence of $-\mathrm{N}=\mathrm{N}-$ (Azo) group. Presence of sharper peak at $1543.9 \mathrm{~cm}^{-1}$ and $1046.09 \mathrm{~cm}^{-1}$ shows the presence of $\mathrm{N}=\mathrm{O}$ group and $\mathrm{S}=\mathrm{O}$ group in resin.

\section{B. Characterization: FE-SEM Analysis}

The physical morphologies and surface properties of the adsorbent were examined by using scanning electron microscopy technique (FE-SEM). Impregnated and used impregnated resin (i.e. after adsorption of RB-13 dye) showed severe differences, a surface of the impregnated resin contained more pores than the surface of used SIR and this results in the higher surface area. It observed from both the Fig. 3(a) and 4(a), that adsorption of RB-13 dye in impregnated XAD-7 resin increases the denseness of the surface. It's also shown FE-SEM analysis spectrum by the Fig. 3 and 4 , that weight $\%$ of $\mathrm{C}, \mathrm{O}, \mathrm{Cl}$ was increased after impregnation and there also shows presence of some new components i.e. $\mathrm{N}, \mathrm{S}, \mathrm{Na}$ in used SIR XAD-7 due to adsorption of RB-13 dye. These new elements are present in RB-13 dye structure, so increment in weight \% and presence of these new elements confirms the adsorption of RB-13 dyes in impregnated XAD-7 resin surface.

\section{Impregnated XAD-7 Resin}

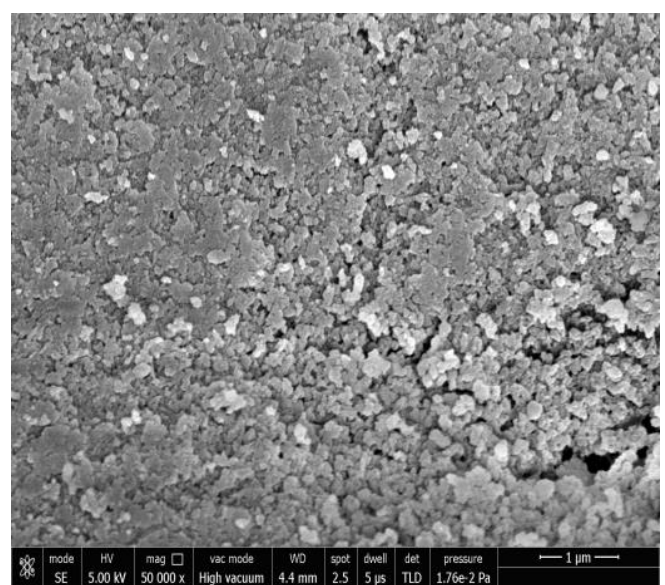

(a)

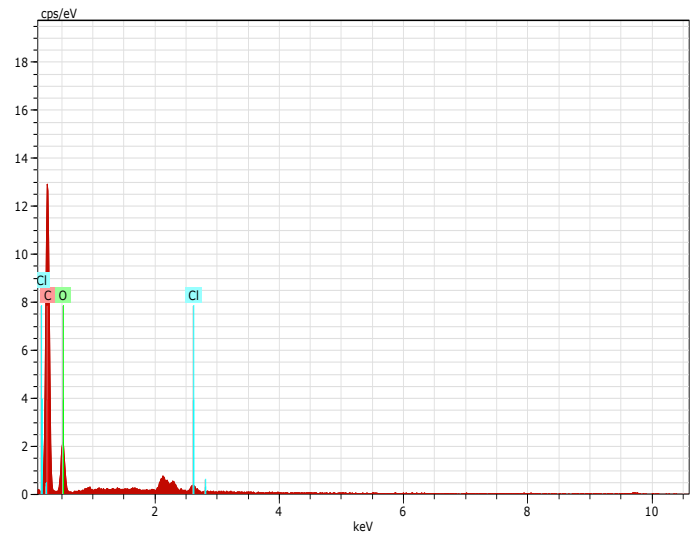

Spectrum: Acquisition 2182

El AN Seriesunn. C norm. C Atom. C Error(1Sigma) [wt.\%] [wt.\%] [at.\%] [wt.\%]

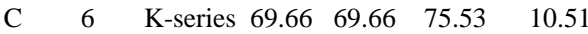

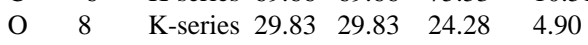

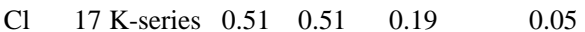

Total: 100.00100 .00100 .00

(b)

Fig. 3. (a) FE-SEM image of impregnated XAD-7 at $50000 \times$ magnification (b) EDS image of impregnated XAD-7.

Used Impregnated XAD-7 Resin (i.e. after adsorption Reactive Blue-13 dye in SIR surface)

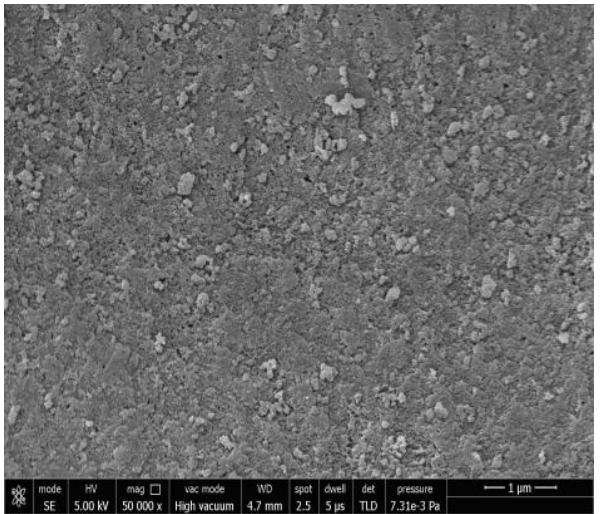

(a)

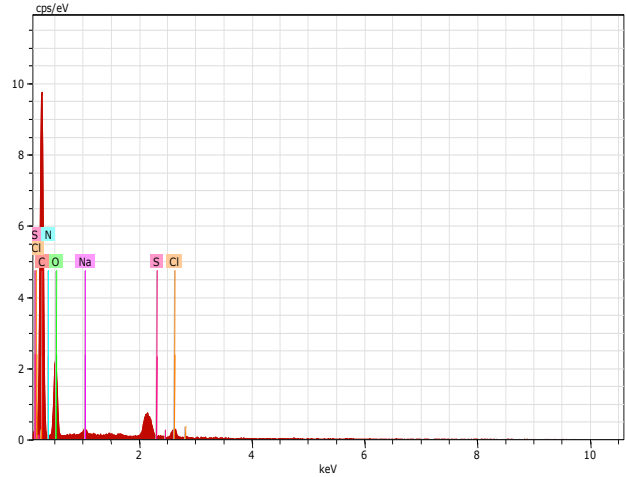

Spectrum: Acquisition 2184

El AN Series unn. C norm. C Atom. C Error (1 Sigma) [wt.\%] [wt.\%] [at.\%] [wt.\%]

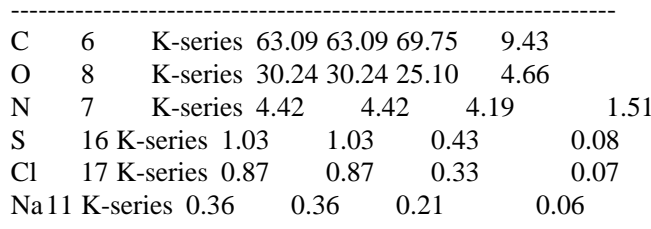

Total: 100.00100 .00100 .00

(b)

Fig. 4. (a) FE-SEM image of used impregnated XAD-7 resin at $50000 \times$ magnification (b) EDS image of used impregnated XAD-7 resin.

\section{Effect of Adsorbent Dosage}

The effect of adsorption dosage on removal of RB-13 dye is shown in Fig. 5. This experiment were performed at various dosage range $0.01-0.3 \mathrm{~g}$ added to $10 \mathrm{ml}$ of predetermined dye concentration solution $50 \mathrm{mg} / \mathrm{L}$, time $2 \mathrm{hr}$ and temperature $303 \mathrm{~K}$. With increase in adsorption dose there also rise in removal efficiency. At $0.1 \mathrm{~g}$ dosage it gives maximum removal of dye $\sim 99 \%$. After that increase in (upto 
$0.3 \mathrm{~g}$ ) adsorbent dosage there was no change observed in dye removal efficiency. So $0.1 \mathrm{~g}$ adsorbent dosage takes as optimum dosage for study of other parameters effect.

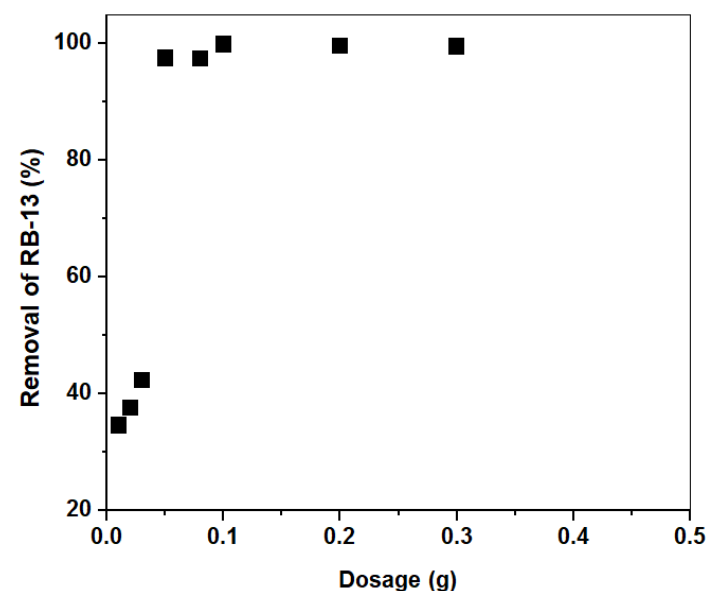

Fig. 5. Effect of adsorbent dosage on adsorption of RB-13 (Initial dye concentration $=50 \mathrm{PPM}, t=2 \mathrm{hr}, \mathrm{T}=303 \mathrm{~K}$ ).

\section{Effect of Contact Time}

The adsorption kinetics behavior of RB-13 dye onto SIR was studied out up to $180 \mathrm{~min}$, by kept different parameter constant. Fig. 6. shows that the concentration of RB-13 dye reduces from its initial value, so the adsorption capacity of SIR inflated sharply upto the initial $60 \mathrm{~min}$ and earned the equilibrium once after $120 \mathrm{~min}$ of contact time. Fig. 6 conjointly shows the intra-particle diffusion model, pseudo $1^{\text {st }}$ order adsorption mechanics, pseudo-second order adsorption mechanics respectively. Pseudo-second order adsorption mechanics shows the most effective suited the experimental data as compared to the other adsorption mechanics model.

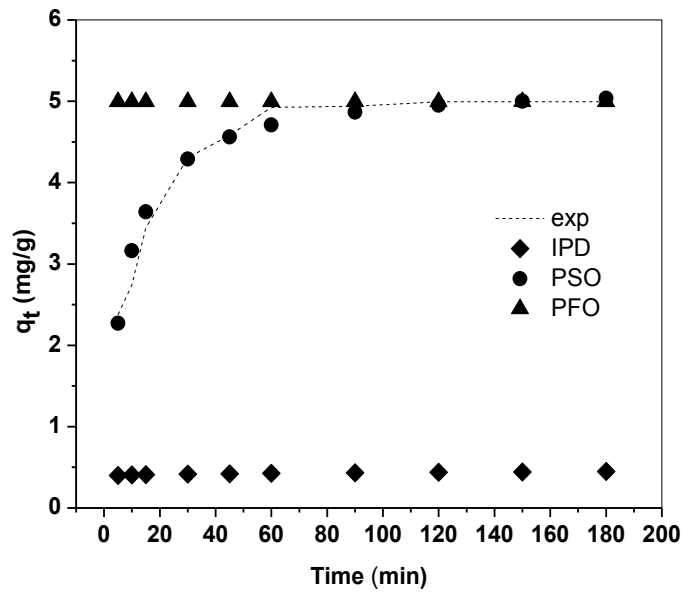

Fig. 6. Kinetics of RB-13 adsorption by Impregnated XAD-7 ( $m=0.1 \mathrm{~g}, \mathrm{C}_{0}=$ 50 PPM, T= $303 \mathrm{~K}$ ).

\section{E. Effect of initial dye Concentration}

Dye concentration effect study was done within the range of $10-500 \mathrm{mg} / \mathrm{L}$ range by kept others parameter constant. As shown in Fig. 7. there was sharply increase in dye removal efficiency from 10 to $30 \mathrm{mg} / \mathrm{L}$ concentration range, after that up to 30 to $50 \mathrm{mg} / \mathrm{L}$ concentration range there was slightly increased in removal efficiency. Then at $50 \mathrm{mg} / \mathrm{L}$ concentration its attend equilibrium, and then up to 50 to 500 $\mathrm{mg} / \mathrm{L}$ concentration range removal efficiency was $99 \%$. At higher concentration range removal was higher. This happened, due to the effect of the concentration gradient. At higher concentration ranges of dyes, there's usually altogether probability that there was chance of rise in driving force. In order that accumulation of dyes occurs around the adsorption sites.

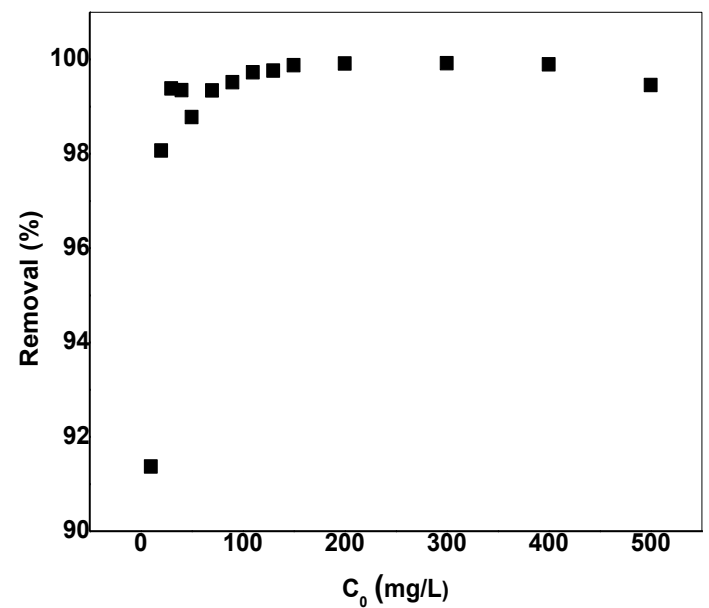

Fig. 7. Effect of RB-13 concentration on the $\%$ removal ( $m=0.1 \mathrm{~g}, t=2 \mathrm{hr}$, $\mathrm{T}=303 \mathrm{~K}$ ).

\section{F. Effect of $p H$}

It can be seen that dye reduction efficiency decreases with an increase in hydrogen ion concentration of the solution. At $\mathrm{pH} 4$, reduction efficiency was maximum near about $99 \%$ and at $\mathrm{pH} 12$ there was a decrease in removal efficiency. So it's an outcome that hydrogen ions concentration plays an important role for removal Anionic dye.

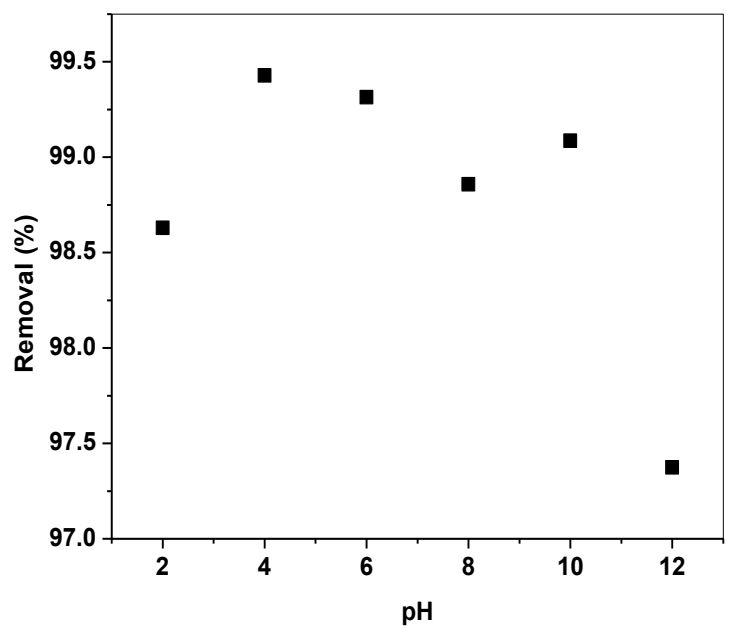

Fig. 8. Effect of $\mathrm{pH}$ on $\%$ removal of RB-13 $(m=0.1 \mathrm{~g}, t=2 \mathrm{hr}, \mathrm{T}=303 \mathrm{~K})$.

\section{G. Effect of Temperature}

Temperature effect studied was done in the varied temperature range 303-333 K. For dye removal process, 303 $\mathrm{K}$ temperature was found to be optimum. It absolutely was found that maximum removal of dye was 99 at $303 \mathrm{~K}$ and slightly decrees in the removal efficiency of dyes until temperature $333 \mathrm{~K}$., therefore, the result shows that temperature has slightly affected the removal efficiency. 


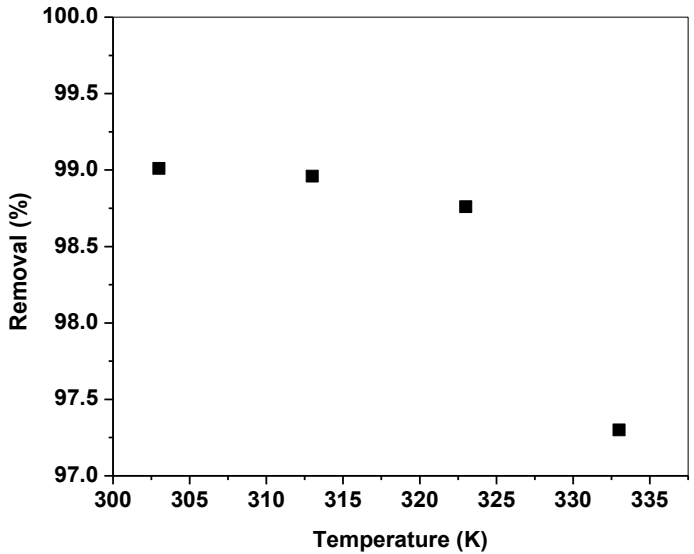

Fig. 9. Temperature effect on percent removal of RB-13 ( $m=0.1 \mathrm{~g}, t=2 \mathrm{hr}$, $\mathrm{C}^{\prime}=50 \mathrm{mg} / \mathrm{L}$ ).

\section{H. Effect of Salt}

As express in the various studies, the concentration of sodium chloride salt in dye solution could improve or diminish adsorption rate. Fig. 10 demonstrated the positive consequence of sodium chloride salt on adsorption. It plainly outlined the ascent in color removal efficiency as the grouping of $\mathrm{NaCl}$ expanded. First this study was performed upto $150 \mathrm{~min}$ at various salt concentrations and by kept other parameters constant, but there no any change was observed in dye concentration. Then by increase in time duration (upto $180 \mathrm{~min}$ ), removal efficiency was also changed. So this experiment was performed at $3 \mathrm{hr}$ time, $0.1 \mathrm{~g}$ dosage, 50 $\mathrm{mg} / \mathrm{L}$ dye solution and 1000-15000 ppm salt concentration. It shown by study that as increase in salt concentration dye removal efficiency was also increased.

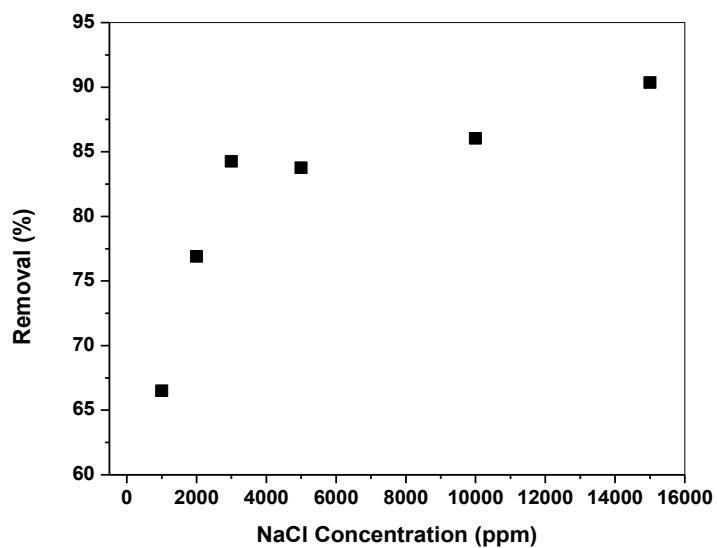

Fig. 10. Effect of Salt on \% removal of RB-13 $\left(\mathrm{m}=0.1 \mathrm{~g}, \mathrm{t}=3 \mathrm{hr}, \mathrm{C}^{\prime} 0=50\right.$ $\mathrm{mg} / \mathrm{L})$.

\section{Regeneration Study}

The used impregnated resin was regenerated with $(80$ v/v) \% ethanol-aqueous solution. Impregnated resin was reused after washing with $(80 \mathrm{v} / \mathrm{v}) \%$ ethanol-aqueous solution upto $30 \mathrm{~min}$ and then again washed with DI water upto $10 \mathrm{~min}$. Then washed resin was oven dried over night. Then this regenerated resin was prepared for reused.

\section{CONCLUSION}

Solvent impregnation resin has good adsorption capacity for removal of RB-13 dye. Characterization of impregnated
XAD-7 resin and used impregnated XAD-7 resin shows adsorption of RB-13 dye due to presence of dye elements. In various parameter effect studies its shows higher removal percent was obtained at lower $\mathrm{pH}$ scale. Pseudo-second order kinetic was best fitting kinetic model. At higher concentration, it shows almost $99 \%$ removal of dyes. Temperature effect on adsorption symbolized that percentage removal decreases slightly as increases in temperature. SIR was reused again after regenerated with $(80 \mathrm{v} / \mathrm{v}) \%$ ethanol aqueous solution. So removal of reactive dye by solvent impregnated resin is more convenient and beneficial technique.

\section{ACKNOWLEDGMENT}

The authors appreciatively thank Malaviya National Institute of Technology, Jaipur, Rajasthan, India, for research support and providing all facilities for experimental work. We tend to additionally acknowledge Material Research Centre Lab, MNIT, Jaipur, for providing the facility of FE-SEM, EDX, and FTIR for characterization of samples. We also thankful to Science \& Engineering Research Board (SERB), a statutory body of the Department of Science \& Technology, New Delhi, India for financial support under Early Career Research Award (EC Engineering Sciences), FILE NO. ECR/2016/001297 to carryout the part of the research (preparation of adsorbent and characterization).

\section{REFERENCES}

[1] T. Robinson, G. McMullan, R. Marchant, and P. Nigam, "Remediation of dyes in textile effluent: A critical review on current treatmen technologies with a proposed alternative," Bioresource Technology, vol. 77, pp. 247-255, May 2001.

[2] Z. Singh and P. Chadha, "Textile industry and occupational cancer," Journal of Occupational Medicine and Toxicology, vol. 11, pp. 39, 2016.

[3] N. Puvaneswari, J. Muthukrishnan, and P. Gunasekaran, "Toxicity assessment and microbial degradation of azo dyes," Indian Journal of Experimental Biology, vol. 44, no. 8, p. 618, 2006.

[4] M. A. Hassaan and A. E. Nemr, "Health and Environmental Impacts of Dyes: Mini Review," American Journal of Environmental Science and Engineering, vol. 1, pp. 64-67, 2017.

[5] E. Moss, "Oral and pharyngeal cancer in textile workers," Ann NY Acad Sci. vol. 271, pp. 301-307, 1976.

[6] E. Buiatti, S. Baccetti, F. Cecchi, A. Tomassini, and P. Dolara, "Evidence of increased lung cancer rate among textile workers," Med Lav., vol. 70, pp. 21-23, 1979.

[7] S. Heyden and P. Pratt, "Exposure to cotton dust and respiratory disease. Textile workers, 'brown lung', and lung cancer," JAMA, vol. 244, pp. 1797-1798, 1980.

[8] E. Delzell and S. Grufferman, "Cancer and other causes of death among female textile workers, 1976-78," J. Natl. Cancer Inst., vol. 71, pp. 735-740, 1983.

[9] L. Levin, Y. T. Gao, W. J. Blot, W. Zheng, and J. F. Jr Fraumeni, "Decreased risk of lung cancer in the cotton textile industry of Shanghai," Cancer Res., vol. 47, pp. 5777-5781, 1987.

[10] T. R. O'Brien and P. Decoufle, "Cancer mortality among northern Georgia carpet and textile workers," Am. J. Ind. Med., vol. 14, pp. 15-24, 1988.

[11] JM. Dement and DP. Brown, "Lung cancer mortality among asbestos textile workers: A review and update," Ann Occup. Hyg., vol. 38, no. 412, pp. 525-532, 1994

[12] C. Serra, X. Bonfill, J. Sunyer, G. Urrutia, D. Turuguet, R. Bastus, M. Roque, A. 't Mannetje, and M. Kogevinas, "Bladder cancer in the textile industry," Scand J. Work Environ Health, vol. 26, pp. 476-481, 2000.

[13] G. Mastrangelo, U. Fedeli, E. Fadda, G. Milan, and J. H. Lange, "Epidemiologic evidence of cancer risk in textile industry workers: A review and update," Toxicol Ind. Health, vol. 18, pp. 171-81, 2002. 
[14] J. H. Lange, G. Mastrangelo, U. Fedeli, R. Rylander, and D. C. Christiani, "A benefit of reducing lung cancer incidence in women occupationally exposed to cotton textile dust," Am J. Ind. Med., vol. 45 , pp. 388-389, 2004.

[15] S. C. Fang, E. A. Eisen, H. Dai, H. Zhang, J. Hang, X. Wang, and D. C. Christiani, "Cancer mortality among textile workers in Shanghai, China: a preliminary study," J. Occup Environ Med., vol. 48, pp. 955-958, 2006.

[16] W. Li, R. M. Ray, D. L. Gao, E. D. Fitzgibbons, N. S. Seixas, J. E. Camp, K. J. Wernli, G. Astrakianakis, Z. Feng, and D. B. Thomas, "Checkoway H. Occupational risk factors for pancreatic cancer among female textile workers in Shanghai," China. Occup Environ Med., vol. 63, pp. 788-793, 2006.

[17] L. A. Tse and I. T. Yu, "Re: 'Occupational exposures and risks of liver cancer among Shanghai female textile workers-a case-cohort study'," Int. J. Epidemiol., vol. 35, p. 1359, 2006.

[18] G. Astrakianakis, N. S. Seixas, R. Ray, J. E. Camp, D. L. Gao, Z. Feng, W. Li, K. J. Wernli, E. D. Fitzgibbons, D. B. Thomas, and H. Checkoway, "Lung cancer risk among female textile workers exposed to endotoxin," J. Natl Cancer Inst., vol. 99, pp. 357-364, 2007.

[19] V. Lenters, I. Basinas, L. Beane-Freeman, P. Boffetta, H. Checkoway, D. Coggon, L. Portengen, M. Sim, I. M. Wouters, D. Heederik, and R. Vermeulen, "Endotoxin exposure and lung cancer risk: a systematic review and meta-analysis of the published literature on agriculture and cotton textile workers," Cancer Causes Control, vol. 21, pp. 523-555, 2010.

[20] H. Checkoway, J. L. Lundin, S. Costello, R. Ray, W. Li, E. A. Eisen, G. Astrakianakis, N. Seixas, K. Applebaum, D. L. Gao, and D. B. Thomas, "Possible pro-carcinogenic association of endotoxin on lung cancer among Shanghai women textile workers," Br J. Cancer, vol. 111, pp. 603-607, 2014

[21] C. O. Neill, F. R. Hawkes, D. L. Hawkes, N. D. Lourenco, H. M Pinherio, and W. Delee, "Colour in textile effluents - sources, measurement, discharge consents and simulation: A review," Journal of Chemical Technology and Biotechnology, vol. 74, no. 11, pp. 1009-1018, 1999.

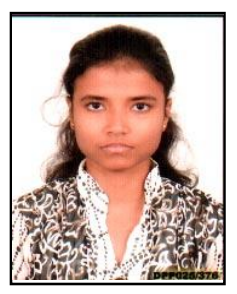

Anjali Awasthi was born in Kanpur, India, in 1990 on April $21^{\text {st }}$. Anjali Awasthi recived the B.Tech degree in chemical engineering from Dr. Ambedkar Institute of Technology for Handicapped, Kanpur, Uttar Pradesh in 2011, and the M.Tech degree in chemical engineering from Harcourt Butler Technical Institute, Kanpur, Uttar Pradesh, in 2013. In June 2010- July 2010, she did internship in Ordnance Factory, Kanpur, Uttar Pradesh and later July 2010-August 2010 did internship in Mayur Edible Oil Factory, Kanpur, Uttar Pradesh. In Feb 2014 she joined the Department of Chemical Engineering, Government
Polytechnic, Kanpur, Uttar Pradesh as a guest lecturer till one semester. In July 2014 - August 2016 she joined the Department of chemical engineering, Harcourt Butler Technical Institute, Kanpur, Uttar Pradesh as Guest Lecturer. In Sept 2016 - 2017 she joined Department of chemical engineering, Dr. Ambedkar Institute of Technology for Handicapped, Kanpur, Uttar Pradesh. She was awarded IICHE NRC award 3rd best paper in "Indian Chemical Engineer" 2016 in CHEMCON 2017, Indian Institute of Chemical Engineers, Haldia, Dec. 27-30, 2017. Her current research interests in wastewater treatment, adsorption and ultra-sonication technique.

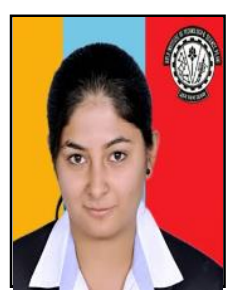

Sakshi Batra was born in Muzaffarnagar, India, in 1991 on July $7^{\text {th }}$. Sakshi Batra received the B.Tech degree in chemical engineering from the Banasthali University, Tonk, Rajasthan, in 2012, and the M.E degree in chemical engineering from the Birla institute of science and technology (BITS), pilani, Rajasthan, in 2015 .

In July 2011- August 2011, she did internship in National fertilizer limited, Vijaypur, Madhya Pradesh and later in Oct 2011 in Chakardhar chemical Pvt. Limited, Muzaffarnagar, Uttar Pradesh. In 2016, she joined the Department of Chemical Engineering, Chandigarh University, Mohali, Punjab, as a lecturer, Since July 2017. Currently she is doing Ph.D. degree in chemical engineering from Malaviya National Institute of Science and technology (MNIT), Jaipur, Rajasthan. Her current research interests in waste water treatment and Adsorption.

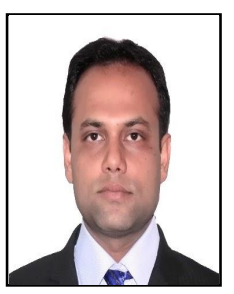

Dipaloy Datta is working as assistant professor in the Department of Chemical Engineering at Malaviya

National Institute of Technology (MNIT), Jaipur, Rajasthan. He earlier worked as an assistant professor, and lecturer in the Department of Chemical Engineering at Thapar University, Patiala, Punjab and at Birla Institute of Technology \&amp; Science (BITS), Pilani, Rajasthan. He earned his bachelor, master and doctoral degree in chemical engineering Pilani, Rajasthan, in the year 2003, 2009 and 2013, respectively. His research areas include adsorption, wastewater treatment, process intensification, reactive extraction, modeling \&amp; simulation and optimization. He has 60 research publications (47 journals, 23 conferences,

1 book and 1 book chapter) to his credit. Dr. Datta is a life associate member of IIChE, member of Indian Desalination Association, and member ACS (2015-18, awarded). 